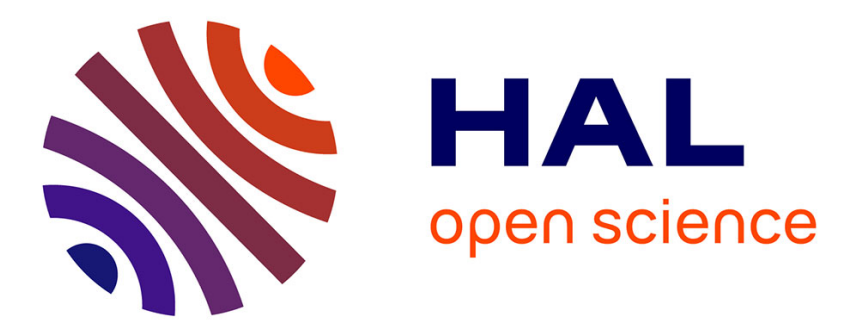

\title{
Kinetic Modeling of the Gas Phase Decomposition of Germane by Computational Chemistry Techniques
}

\author{
M. Hierlemann, H. Simka, K. Jensen, M. Utz
}

\section{To cite this version:}

M. Hierlemann, H. Simka, K. Jensen, M. Utz. Kinetic Modeling of the Gas Phase Decomposition of Germane by Computational Chemistry Techniques. Journal de Physique IV Proceedings, 1995, 05 (C5), pp.C5-71-C5-77. 10.1051/jphyscol:1995505 . jpa-00253761

\section{HAL Id: jpa-00253761 https://hal.science/jpa-00253761}

Submitted on 1 Jan 1995

HAL is a multi-disciplinary open access archive for the deposit and dissemination of scientific research documents, whether they are published or not. The documents may come from teaching and research institutions in France or abroad, or from public or private research centers.
L'archive ouverte pluridisciplinaire HAL, est destinée au dépôt et à la diffusion de documents scientifiques de niveau recherche, publiés ou non, émanant des établissements d'enseignement et de recherche français ou étrangers, des laboratoires publics ou privés. 


\title{
Kinetic Modeling of the Gas Phase Decomposition of Germane by Computational Chemistry Techniques
}

\author{
M. Hierlemann, H. Simka*, K.F. Jensen* and M. Utz** \\ Corporate $R \& D$, Siemens $A G$, München, Germany \\ * Dep. Chem. Eng., Massachusetts Institute of Technology, U.S.A. \\ ** Institut für Polymere, ETH Zürich, Switzerland
}

\begin{abstract}
Very limited experimental data are available on thermal decomposition of germane in the gas phase. Recent developments in theoretical quantum chemistry techniques such as $a b$ initio Hartree-Fock and density functional methods have made accurate determination of molecular properties possible. Systematic development of a detailed gas-phase decomposition mechanism for germane using ab initio molecular orbital calculations is described in this work. A decomposition pathway for germane and higher germanes is proposed and the relevant reaction rates are calculated using transition state theory combined with unimolecular and chemical activation treatments. The decomposition model is implemented into a realistic thermal-fluid simulation.
\end{abstract}

\section{INTRODUCTION}

$\mathrm{Si}_{1-x} \mathrm{Ge}_{x}$ alloys have recently attracted considerable attention as a material for manufacturing high speed electronic devices like high-electron mobility transistors (HEMT's) and heterojunction bipolar transistors (HBT's) or various optoelectronic devices. The composition of the deposited $\mathrm{Si}_{1-x} \mathrm{Ge}_{x}$ alloys strongly affects device performance. Controllability of composition as well as of film thickness is one of the key limitations in wafer processing. Hence, the knowledge of epitaxial growth kinetics is very important, especially as device dimensions continue to reduce.

Very limited experimental data exist for the gas-phase pyrolysis of $\mathrm{GeH}_{4}$. In this work ab initio molecular orbital (MO) calculations [1] are applied to $\mathrm{GeH}_{4}$ decomposition. Heats of formation of the relevant species and transition state configurations are calculated and reaction barriers for several possible reactions are predicted. The reaction rates for the most probable decomposition pathway are calculated using conventional transition state theory combined with unimolecular and chemica! activation treatments. The agreement between calculated and measured reaction rates is found to be very good. The importance of the individual reactions of the decomposition path is evaluated by thermal-fluid simulations in a realistic reactor geometry.

\section{2. $A B$ INITIO CALCULATIONS}

All molecular properties of a given molecule can in principle be calculated by solving the Schrödinger equation (in Dirac notation)

$$
\mathcal{H}|\boldsymbol{\Psi}>=E| \boldsymbol{\Psi}>
$$

where $\mathcal{H}$ is the Hamiltonian describing the total energy of the system and $\boldsymbol{\Psi}$ is the many-particle wave-function which depends on the coordinates and spins of all $n$ particles

$$
|\boldsymbol{\Psi}\rangle=\left|\boldsymbol{\Psi}\left(\vec{r}_{1}, \omega_{1}, \vec{r}_{2}, \omega_{2}, \ldots, \vec{r}_{n}, \omega_{n}\right)\right\rangle .
$$


The mathematical difficulties involved in solving the Schrödinger equation make it impossible to attempt an exact solution even for small molecules. The Born-Oppenheimer approximation allows a separate treatment of electronic and nuclear motions. The Hartree-Fock approximation replaces repulsion between individual electrons by an average potential of all electrons. The now simplified time independent Schrödinger equation states an eigenvalue problem. The variational method determines the minimal energy wave function $\left|\boldsymbol{\Psi}^{\prime}\right\rangle$ which is the best estimate to the exact solution. In general $\left|\boldsymbol{\Psi}^{\prime}\right\rangle$ will be such a complicated function that there is no simple way to find the energy minimum. However, if only linear variations of the trial function are allowed, i.e.

$$
\left|\boldsymbol{\Psi}^{\prime}\right\rangle=\sum_{i=1}^{n} c_{i}\left|\boldsymbol{\Phi}_{i}\right\rangle
$$

with [ $\left.\left|\boldsymbol{\Phi}_{i}\right\rangle\right]$ being a set of fixed basis functions, then finding the optimum set of coefficients $c_{i}$ is reduced to a matrix diagonalization problem.

In the Hartree Fock (HF) approximation each electron pair is assigned its own orbital and interelectronic repulsion is treated in an average way. Physically, electrons do not obey a static dis. tribution but interact with each other instantaneously. The most common method to improve HF wave-functions in this respect and to correct for electron correlation effects is applying Møller-Plesset (MP) perturbation theory or configuration interaction (CI) [2].

\subsection{Used methodology}

MO theory is used to calculate the molecular properties of individual Ge species from first principles. The calculations are performed at restricted Hartree Fock (RHF) and unrestricted Hartree Fock (UHF) level using the software Gamess [3]. The theoretical equilibrium geometries and harmonic vibrational frequencies are determined at the $\mathrm{HF} / \mathrm{BC}(2 \mathrm{p}, 3 \mathrm{~d})$ level of theory (Hartree-Fock theory using the $\mathrm{BC}(2 \mathrm{p}, 3 \mathrm{~d})$ basis set [4]). Frequencies computed at $\mathrm{HF}$ level of theory are systematically larger than the corresponding experimental values. This systematic deficiency is corrected by scal. ing the vibrational frequencies by a factor of 0.89 [1]. The energy calculations are performed at MP2/BC(2p,3d) and MP2/BC(1d,1f) level (second order Møller-Plesset perturbation theory using the $\mathrm{BC}(2 \mathrm{p}, 3 \mathrm{~d})$ and $\mathrm{BC}(1 \mathrm{~d}, 1 \mathrm{f})$ basis sets $)$ based on the $\mathrm{HF} / \mathrm{BC}(2 \mathrm{p}, 3 \mathrm{~d})$ geometries. No bond order correction factors for $\mathrm{Ge}-\mathrm{H}$ or $\mathrm{Ge}-\mathrm{Ge}$ bonds are introduced.

The accuracy of $a b$ initio MO calculations depends largely on the size of the chosen basis set. the quality of the basis set in regard to the molecules to be investigated and the level of theory to correct for correlation effects. More accurate calculations significantly increase calculation time. $\mathrm{CI}$, even with a minimal basis set, is computationally expensive for heavier molecules. MP perturbation theory can be applied at different orders. Higher order means better accuracy but also increased calculation time. We chose a high quality basis set together with second-order MP perturbation theory to limit the computational effort but still obtain results with sufficient accuracy for CVD simulations.

In general, heats of formation, $\Delta H_{f}^{0}$, are calculated by subtracting the total energy of the given species at reference state from the equilibrium total energy, e.g.

$$
\begin{gathered}
\mathrm{Ge}(\mathrm{s})+2 \mathrm{H}_{2}(\mathrm{~g}) \longrightarrow \mathrm{GeH}_{4}(\mathrm{~g}) \\
\Delta H_{f, G_{e} H_{4}(s)}^{0}=E_{t o t, G e H_{4}(g)}-E_{t o t, G e(g)}-2 E_{t o t, H_{2}(g)}+\Delta H_{s u b, G e(s)}^{0}
\end{gathered}
$$

where $E_{\text {tot }}$ is the sum of electronic, vibrational, rotational and translational energy and $\Delta H_{s u b, G e(s)}^{0}$ is the standard sublimation enthalpy of solid $\mathrm{Ge}$ [5]. In the reaction expression (4), the number of valence electron pairs on the product side is larger than on the reactant side. Consequently, the correlation energy is not balanced, which introduces systematic errors. The isogyric approach [1] is used to minimize this effect

$$
\mathrm{Ge}(\mathrm{s})+3 \mathrm{H}_{2}(\mathrm{~g}) \longrightarrow \mathrm{GeH}_{4}(\mathrm{~g})+2 \mathrm{H}(\mathrm{g})
$$




\begin{tabular}{lcccc}
\hline & \multicolumn{4}{c}{ Heats of Formation $\Delta H_{f^{0}}^{0}[\mathrm{kcal} /$ mole $]$} \\
\cline { 2 - 5 } Molecule & $\mathrm{BC}(2 \mathrm{p}, 3 \mathrm{~d})$ & $\mathrm{BC}(\mathrm{Id}, 1 \mathrm{f})$ & Theory & Experiment \\
\hline $\mathrm{GeH}_{4}$ & 12.9 & 17.8 & $16.8(19.6)$ & $\leq 21.7^{b}$ \\
$\mathrm{GeH}_{3}$ & 47.5 & 51.3 & $50.0(52.8)$ & $\leq 58.1^{c}, 54.7 \pm 2^{c}, 55.2 \pm 2^{d}, 50.6^{c}$ \\
$\mathrm{GeH}_{2}\left({ }^{1} A_{1}\right)$ & 56.7 & 57.5 & $56.4(59.2)$ & $\geq 59.3^{c}, 61.9^{c}, 60.4 \pm 3.8^{d}$ \\
$\mathrm{GeH}_{2}\left({ }^{3} B_{1}\right)$ & 80.0 & 83.3 & $82.0(84.4)$ & \\
$\mathrm{GeH}_{\mathrm{Ge}}$ & 75.7 & 75.7 & $74.9(76.0)$ & $\leq 86.0^{c}, 76.8^{c}$ \\
$\mathrm{HGeGeH}_{3}$ & 22.0 & 30.2 & & $\leq 38.8^{b}$ \\
$\mathrm{H}_{2} \mathrm{GeGeH}_{2}$ & & 68.6 & & \\
\hline \hline
\end{tabular}

Sublimation Energy of Ge: $88.2 \mathrm{kcal} / \mathrm{mole}^{c}$

Dissociation Energy of $\mathrm{H}_{2}: 103.3 \mathrm{kcal} / \mathrm{mole}^{f}$

${ }^{a}$ R.C. Binning, L.A. Curtiss, J. Chem. Phys., 92, 2, 1860, (1990)

Values in parentheses include estimates of spin-orbit corrections.

${ }^{b} \mathrm{CRC}$ Handbook of Physics and Chemistry, The Chemical Rubber Company, 73, (1993)

${ }^{c}$ B. Ruscic, M. Schwarz and J. Berkowitz, J. Chem. Phys. 92, 1865 (1990)

${ }^{d}$ P.N. Noble and R. Walsh, Int. J. Chem. Kinetics, 15, 547 (1983)

${ }^{e}$ B.S. Agrawala and D.W. Setser, J. Chem. Phys. 86, 5421 (1987)

J JANAF Thermochemical Tables, Natl. Stand. Ref. Data Ser., NIST

Table 1: Comparison of calculated vs measured and predicted heats of formation.

Here the number of electron pairs on the right-hand side and the left-hand side is balanced. The heat of formation of $\mathrm{GeH}_{4}$ is calculated according to

$$
\Delta H_{f, G e H_{4}(g)}^{0}=E_{t o t, G e H_{4}(g)}+2 E_{t o t, H(g)}-E_{t o t, G e(g)}-3 E_{t o t, H_{2}(g)}-B D E_{H_{2}(g)}+\Delta H_{s u b, G e(s)}^{0}
$$

with $B D E_{H_{2}(g)}$ being the experimental bond dissociation energy of $\mathrm{H}_{2}$ [6].

\subsection{Results and discussion}

Heats of formation for several Ge species calculated with the $\mathrm{BC}(2 \mathrm{p}, 3 \mathrm{~d})$ and the $\mathrm{BC}(1 \mathrm{~d}$, If $)$ basis set at a reference state of $0 \mathrm{~K}$ are listed in table 1 along with recently calculated values of Binning and Curtiss (MP4/962(d,p)) [4] and available experimental data. The uncertainty of the calculated numbers is estimated to be around $4 \mathrm{kcal} /$ mole. This includes a general estimated uncertainty of $\approx 2-3 \mathrm{kcal} / \mathrm{mole}$ associated with the accuracy of the HF/MP2 calculations and the uncertainties in the sublimation energy of $\mathrm{Ge}$ and the bond dissociation energy of $\mathrm{H}_{2}$. Calculated heats of formation for the $\mathrm{BC}(1 \mathrm{~d}, 1 \mathrm{f})$ basis set are much closer to the experimental values and Binning and Curtiss' theoretical predictions than are those for the $\mathrm{BC}(2 \mathrm{p}, 3 \mathrm{~d})$ basis set. The $\mathrm{BC}(1 \mathrm{~d}, 1 \mathrm{f})$ calculations are much closer to the HF limit which is the best value for the minimum energy.

Predicted heats of formation for species with only one Ge atom agree very well with experimental data and the MP4 calculations of Binning and Curtiss. For species with two Ge atoms there is only the experimental heat of formation for $\mathrm{Ge}_{2} \mathrm{H}_{6}$ available [6]. The discrepancy between this value and the one predicted cannot be attributed solely to uncertainties in the calculations. The problem could be due to deficiencies of the $\mathrm{BC}(1 \mathrm{~d}, 1 \mathrm{f})$ basis set which might properly describe a $\mathrm{Ge}-\mathrm{H}$ bond but not the Ge-Ge bond.

The predicted reaction barriers are displayed in table 2. It is energetically more favourable for $\mathrm{GeH}_{4}$ to loose $\mathrm{H}_{2}$ in an initial decomposition step rather then $\mathrm{H}$, since the latter reaction requires a more than $30 \mathrm{kcal} /$ mole higher activation energy. Reactions involving hydrogen radicals, i.e $\mathrm{GeH}_{4}$ $+\mathrm{H} \longrightarrow \mathrm{GeH}_{3}+\mathrm{H}_{2}$ or $\mathrm{GeH}_{3}+\mathrm{H} \longrightarrow \mathrm{GeH}_{2}+\mathrm{H}_{2}$, have very low activation barriers. However, 


\begin{tabular}{|c|c|c|c|c|c|c|}
\hline & \multirow{3}{*}{\multicolumn{2}{|c|}{ Reaction }} & \multicolumn{4}{|c|}{ Reaction Barriers $E_{0}[\mathrm{kcal} / \mathrm{mole}]$} \\
\hline & & & \multicolumn{2}{|c|}{ forward barrier } & \multicolumn{2}{|c|}{ reverse barrier } \\
\hline & & & $\mathrm{BC}(2 \mathrm{p}, 3 \mathrm{~d})$ & $\mathrm{BC}(1 \mathrm{~d}, 1 \mathrm{f})$ & $\mathrm{BC}(2 \mathrm{p}, 3 \mathrm{~d})$ & $\mathrm{BC}(1 \mathrm{~d}, 1 \mathrm{f})$ \\
\hline $\mathrm{GeH}_{4}$ & $\longrightarrow$ & $\mathrm{GeH}_{2}+\mathrm{H}_{2}$ & 56.6 & 55.3 & 13.4 & 16.2 \\
\hline $\mathrm{GeH}_{4}$ & $\longrightarrow$ & $\mathrm{GeH}_{3}+\mathrm{H}\left({ }^{1} A_{1}\right)$ & 89.9 & 89.0 & 4.1 & 3.8 \\
\hline $\mathrm{GeH}_{4}$ & $\longrightarrow$ & $\mathrm{GeH}_{3}+\mathrm{H}\left({ }^{3} B_{1}\right)$ & 92.2 & 91.6 & 6.3 & 6.5 \\
\hline $\mathrm{GeH}_{4}+\mathrm{H}$ & $\longrightarrow$ & $\mathrm{GeH}_{3}+\mathrm{H}_{2}$ & 5.6 & 6.2 & 22.9 & 24.9 \\
\hline $\mathrm{GeH}_{3}+\mathrm{H}$ & $\longrightarrow$ & $\mathrm{GeH}_{2}+\mathrm{H}_{2}$ & 5.4 & 6.1 & 48.1 & 52.2 \\
\hline $\mathrm{GeH}_{4}+\mathrm{GeH}_{2}$ & $\longrightarrow$ & $\mathrm{Ge}_{2} \mathrm{H}_{6}$ & & $\approx 0$ & & 44.5 \\
\hline $\mathrm{Ge}_{2} \mathrm{H}_{6}$ & $\longrightarrow$ & $\mathrm{HGeGeH}_{3}+\mathrm{H}_{2}$ & & 49.6 & & 11.7 \\
\hline $\mathrm{HGeGeH}_{3}$ & $\longrightarrow$ & $\mathrm{H}_{2} \mathrm{GeGeH}_{2}$ & & 9.9 & & 10.6 \\
\hline
\end{tabular}

Table 2: Calculated reaction barriers.

the hydrogen radical concentration in the gas phase is close to zero for typical CVD conditions 5 that these reactions can be neglected. $\mathrm{GeH}_{2}$ can react with $\mathrm{GeH}_{4}$ without additional activation. The resulting $\left(\mathrm{Ge}_{2} \mathrm{H}_{6}\right)^{*}$ is vibrationally energized. It can either undergo collisional stabilization, react via a chemically activated pathway to form $\mathrm{HGeGeH}_{3}$ and $\mathrm{H}_{2}$, or react along the the original pathwa: to re-form the reactants. The chemically activated channel

$$
\mathrm{GeH}_{2}+\mathrm{GeH}_{4} \longleftrightarrow\left(\mathrm{Ge}_{2} \mathrm{H}_{6}\right)^{*} \longrightarrow \mathrm{HGeGeH}_{3}+\mathrm{H}_{2}
$$

extends the decomposition pathway to the formation of $\mathrm{HGeGeH}_{3}$ and $\mathrm{H}_{2} \mathrm{GeGeH}_{2} . \mathrm{HGeGeH}_{3}$ isome: izes with an activation barrier of about $10 \mathrm{kcal} /$ mole to form $\mathrm{H}_{2} \mathrm{GeGeH}_{2}$. The outlined decomposition path is visualized in figure 1 . The activated channel represents a 'short cut' on the sketched energ: surface. The proposed decomposition pathway for $\mathrm{GeH}_{4}$ is similar to $\mathrm{SiH}_{4}$ decomposition $[7,8$ and references within].

\section{RATE CONSTANTS}

Transition state theory (TST) is widely used to interpret or estimate rate data. TST requires no calculations on the dynamics of the reacting system. A characteristic of unimolecular reactions is the dependence of the rate constant on collisional energy transfer. This results in a direct dependence of the overall rate constant on the pressure of the bath gas. The application of TST to unimolecula: reactions results only in the rate constant at the high pressure limit, $k_{u n i}^{\infty}$. It does not allow the esti mation of the pressure dependence of the unimolecular rate constant, $k_{\text {uni }}(p)$. Other techniques like Rice-Ramsperger-Kassel-Marcus (RRKM) treatment or Quantum-Rice-Ramsperger-Kassel (QRRhi analysis must be considered.

RRKM theory is based on two major assumptions: (1) the existence of a critical geometry a: required for TST and (2) the ergodicity hypothesis. The ergodicity hypothesis states that intramolec ular energy transfer is rapid compared to reaction. The program that has been used in this work for performing the RRKM calculations is the UNIMOL program suite by Gilbert et al. [9]. UNimol provides the biased random walk (BRW) model for calculating the collisional energy transfer. The Lennard-Jones parameters for the Ge species, required for the RRKM calculations, are calculated according to the procedures outlined by Coltrin and coworkers [10]. The rate coefficient for the re. verse recombination reaction, $k_{\text {rec }}$, can be obtained from the forward rate, $k_{u n i}$, and the equilibrium constant.

The calculation of the rate constant for reaction systems involving a chemically activated cliannd is determined by competition among all possible reactions: i) stabilization by collisions, ii) redissoci. ation into reactants and iii) formation of new products by dissociation or isomerization. The analysis 


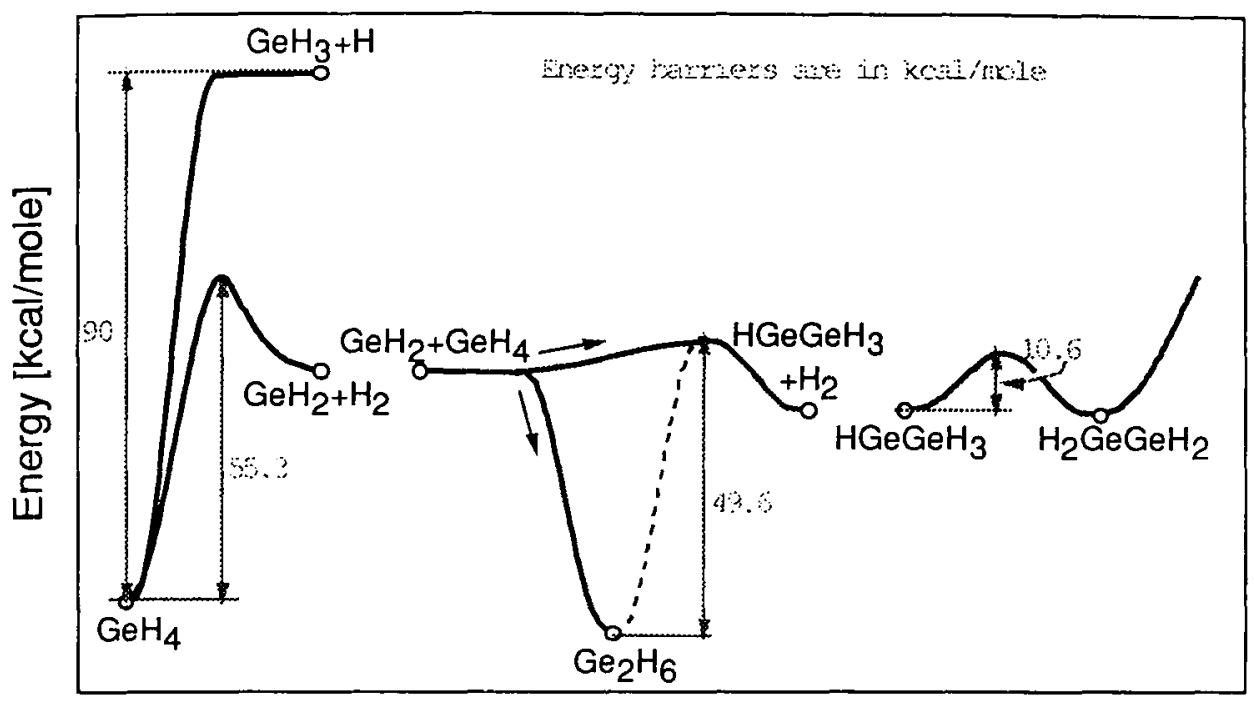

Reaction Coordinate

Figure 1: Energetics of major decomposition path

by RRKM methods for this type of reaction system is very complicated and not yet fully developed. Therefore, the QRRK method proposed by Dean and Westmoreland [11] in similar combustion reactions is applied. Predictions of rate constants bu QRRK need only very few molecular structure and thermodynamic data; no transition state parameters are required.

\subsection{Discussion of predicted rate constants}

Figure 2 shows predicted falloff curves for the decomposition of $\mathrm{GeH}_{4}$ into $\mathrm{GeH}_{2}$ and $\mathrm{H}_{2}$ at temperatures of $800 \mathrm{~K}, 1000 \mathrm{~K}$ and $1200 \mathrm{~K}$. The falloff curves have been generated using RRKM analysis. Ring, O'Neal and coworkers have investigated this reaction by means of shock tube experiments [12]. At a pressure of 4000 torr and temperatures around $1000 \mathrm{~K}$ they measured a rate constant of $\log k_{\mathrm{GeH}_{4}, 4000}=13.83 \pm 0.78-50750 \pm 3750 \mathrm{cal} / 2.303 R T$. They estimated the high pressure rate constant by fitting RRKM calculations to their data to $\log k_{G e H_{4}, \infty}=15.5-54300 \mathrm{cal} / 2.303 R T$. Their high pressure limit is in good agreement with the $\log k_{G e H_{4}, \infty}=15.5-52100 \mathrm{cal} / 2.303 R T$ reported by Votintsev and coworkers [13]. Our theoretical calculations result in a pressure independent activation energy of $E_{a}(T=1000 K)=56.2 \mathrm{kcal} /$ mole. The predicted rate constants are $\log k_{G_{e} H_{\mathbf{4}}, 4000}=13.6-56.2 \mathrm{kcal} / 2.303 R T$ and $\log k_{G e H_{4}, \infty}=14.3-56.2 \mathrm{kcal} / 2.303 R T$. These rate constants are slightly lower than the ones reported by Ring, O'Neal and coworkers; however, our predicted $k_{\mathrm{GeH}_{4}, 4000}$ is still inside the error limits of the measurement. Su and Schlegel calculated the high pressure rate constant for unimolecular decomposition of $\mathrm{SiH}_{4}$ into $\mathrm{SiH}_{2}$ and $\mathrm{H}_{2}$ from ab initio calculations [14]. Similar to our result they compute a pre-exponential factor an order of magnitude smaller than the experimentally derived value. They attribute this difference to a small exit barrier and a strongly bound complex, which means that the silane decomposition should be treated by a variational transition state approach. A similar conclusion was drawn by Moffat et al. [8] in the analysis of a large number of experimental studies.

The $\mathrm{GeH}_{2}$ created by elimination of $\mathrm{H}_{2}$ from $\mathrm{GeH}_{4}$ further reacts with $\mathrm{GeH}_{4}$. This reaction branches the decomposition path into i) stabilization of the activated $\left(\mathrm{Ge}_{2} \mathrm{H}_{6}\right)^{*}$ and ii) activated dissociation to form $\mathrm{HGeGeH}_{3}$ and $\mathrm{H}_{2}$. The rate constants for stabilization and activated dissociation have been calculated by the QRRK method. The results are displayed in figure 3 . The rate constant 
of the chemically activated channel is pressure independent according to the bimolecular charact: of the reaction. Unimolecular stabilization of $\left(\mathrm{Ge}_{2} \mathrm{H}_{6}\right)^{*}$ increases linearly with respect to pressure: the low pressure regime. The activated channel dominates over stabilization at high temperatur: and low pressures.

The stabilized $\mathrm{Ge}_{2} \mathrm{H}_{6}$ also forms $\mathrm{HGeGeH}_{3}$ and $\mathrm{H}_{2}$. This reaction is embedded in the reactic: network associated with the activated decomposition of exited $\left(\mathrm{Ge}_{2} \mathrm{H}_{6}\right)^{*}$. The rate constants ar: therefore estimated using the QRRK technique. $\mathrm{HGeGeH}_{3}$ isomerizes in to $\mathrm{H}_{2} \mathrm{GeGeH}_{2}$. The activatio: energy for the isomerization is low, $E_{a}=9.9 \mathrm{kcal} / \mathrm{mole}$. Hence, if $\mathrm{HGeGeH}_{3}$ is formed, it would be expected to readily isomerize into ${ }_{2} \mathrm{GeGeH}_{2}$.

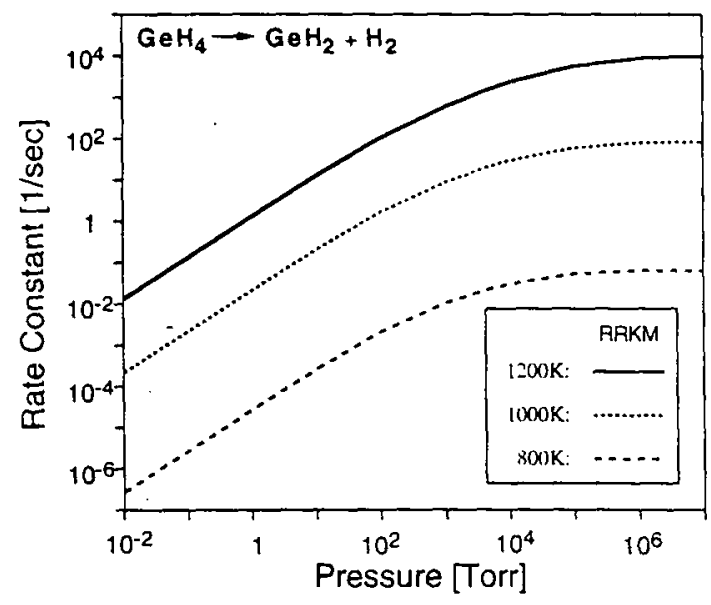

Figure 2: Rate constants for unimolecular decomposition of $\mathrm{GeH}_{4}$.

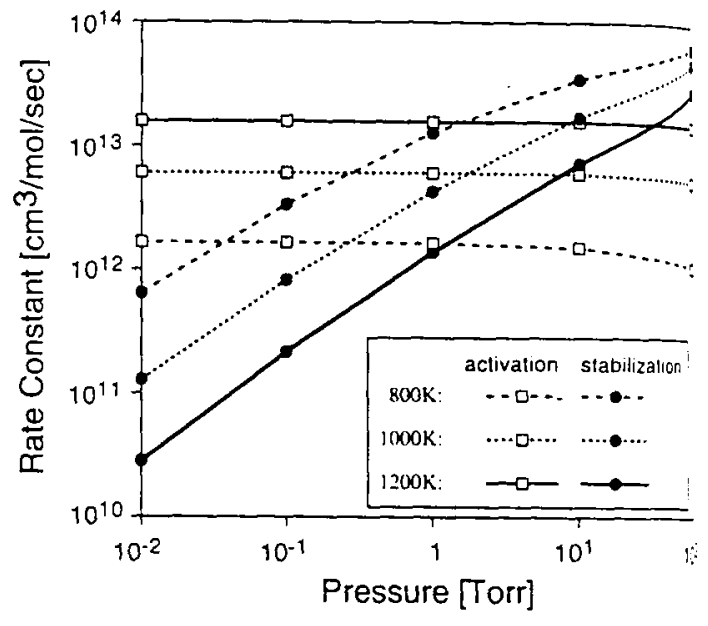

Figure 3: Comparison of rate constants for the activation and stabilization reactions.

\section{CVD SIMULATIONS}

The developed kinetic model for gas-phase pyrolysis of $\mathrm{GeH}_{4}$ is implemented into a realistic therm?! fluid simulation of an existing CVD reactor. The reactor is described elsewhere [15]. For the presen: studies the reactor is modeled as being isothermal. Typical process conditions are assumed: the flor rate is $1000 \mathrm{sccm} \mathrm{H}_{2}$ with $10 \mathrm{sccm} \mathrm{GeH}_{4}$, the temperature is between $800 \mathrm{~K}$ and $1000 \mathrm{~K}$ and th: pressure varies from 1 torr to 10 torr.

There is basically no decomposition of $\mathrm{GeH}_{4}$ at a temperature of $800 \mathrm{~K}$ and a pressure of 1 tori This result is not surprising since the the activation energy for the initial decomposition step is quit high, $E_{a}=56 \mathrm{kcal} / \mathrm{mole}$. The abundance of $\mathrm{H}_{2}$ promotes the reverse reaction and therefore inhibit: decomposition further. The mole fractions of decomposition products in the reactor are about fir orders of magnitude lower than the $\mathrm{GeH}_{4}$ mole fractions. Increasing the temperature to $1000 \mathrm{~K}$ at : torr introduces a weak initial decomposition of $\mathrm{GeH}_{4}$. Still the amount of $\mathrm{GeH}_{4}$ decomposed is less than $1 \%$. The generated $\mathrm{GeH}_{2}$ immediately reacts with $\mathrm{GeH}_{4}$ to form $\mathrm{Ge}_{2} \mathrm{H}_{6}$ and $\mathrm{HGeGeH}_{3}$. The mole fractions of $\mathrm{HGeGeH}_{3}$ or $\mathrm{H}_{2} \mathrm{GeGeH}_{2}$ are one order of magnitude higher than the ones of $\mathrm{Ge}_{2} \mathrm{H}_{6}$ This indicates that the activated channel dominates stabilization of $\left(\mathrm{Ge}_{2} \mathrm{H}_{6}\right)^{*}$.

At a pressure of 10 torr decomposition increases significantly at all temperatures. For $T=1000$ $\mathrm{K}$ the $\mathrm{GeH}_{4}$ inlet mole fraction is reduced $15 \%$ in the reactor. Again the reaction of $\mathrm{GeH}_{2}$ with GeH. is very fast (the mole fractions of $\mathrm{GeH}_{2}$ are 1 to 2 orders of magnitude lower than the ones of thr other pyrolysis species). The significant difference from the 1 torr simulations is the ratio of $\mathrm{Ge}_{2} \mathrm{H}$ (the stabilized species) to $\mathrm{HGeGeH}_{3}$ and $\mathrm{H}_{2} \mathrm{GeGeH}_{2}$ (the products of the activated channel). The mole fractions of all these species are in the same order of magnitude, indicating that the actirated channel is not dominating stabilization any more. Activation and stabilization are both important. 
Gas phase decomposition of germane and higher germanes is significant in CVD at temperatures above $800 \mathrm{~K}$ and pressures above 10 torr. In modeling approaches it is important to include not only the initial decomposition of $\mathrm{GeH}_{4}$ but to extend the kinetic model to higher germanes. Analogous to the silane system the higher germanes are potentially more efficient for Ge film deposition since with each precursor molecule multiple Ge atoms adsorb on the surface.

\section{CONCLUSIONS}

Computational chemistry is capable of closing the gap between the availability of experimental data and the need for kinetic information in modeling microelectronics deposition processes. Quantum chemistry techniques deliver thermochemical properties in good agreement with measured quantities. A careful selection of the basis set and the inclusion of the major correlation corrections using secondorder MP perturbation theory gives sufficiently accurate results and keeps calculation time inside reasonable limits. This makes quantum chemistry techniques attractive not only for the academic community but also for engineering applications. The thermochemical data can be interpreted by TST, RRKM and QRRK calculations to predict rate constants. The developed kinetic model can easily be implemented in a thermal-fluid simulation of a given CVD reactor.

\section{References}

[1] W. J. Hehre, L. Radom, P. v.R. Schleyer, and J. A. Pople. Ab initio Molecular Orbital Theory. John Wiley \& Sons, New York, 1986.

[2] A. Szabo and N. S. Ostlund. Modern Quantum Chemistry. McGraw-Hill, New York, 1989.

[3] M. W. Schmidt, K. K. Baldridge, J. A. Boatz, S. T. Elbert, M. S. Gordon, J. H. Jensen, S. Koseki, N. Matsunaga, K. A. Nguyen, S. Su, T. L. Windus, M. Dupuis, and J. A. Montgomery. J. Comput. Chem., 14:1347, 1993.

[4] R. C. Binning Jr. and L. A. Curtiss. J. Chem. Phys., 92:1860, 1990.

[5] B. Ruscic, M. Schwarz, and J. Berkowitz. J. Chem. Phys., 92:1865, 1990.

[6] National Bureau of Standards. JANAF Thermochemical Tables. Natl. Stand. Ref. Data Ser., Gaithersburg.

[7] M. E. Coltrin, R. J. Kee, and G. H. Evans. J. Electrochem. Soc., 136:819, 1989.

[8] H. K. Moffat, K. F. Jensen, and R. W. Carr. J. Phys. Chem., 96:7695, 1992.

[9] R. G. Gilbert, S. C. Smith, and M. J. T. Jordan. Unimol program suite. School of Chemistry Sidney University.

[10] M. E. Coltrin, R. J. Kee, and J. A. Miller. J. Electrochem. Soc., 133:1206, 1986.

[11] P. R. Westmoreland, J. B. Howard, J. P. Longwell, and A. M. Dean. AIChE Journal, 32:1971, 1986.

[12] C. G. Newman, J. Dzarnoski, M. A. Ring, and H. E. O'Neal. Int. J. Chem. Kin., 12:661, 1980.

[13] V. N. Votintsev, I. S. Zaslonko, V. S. Mikheev, and V. N. Smirnov. Kinetika et Kataliz, 26:1303, 1985.

[14] M. D. Su and H. B. Schlegel. J. Phys. Chem., 97:9981, 1993.

[15] M. Hierlemann, A. Kersch, C. Werner, and H. Schäfer. J. Electrochem. Soc., 142:259, 1995. 